NASA/TM-2006-214261

\title{
The Role of Flight Experiments in the Development of Cryogenic Fluid Management Technologies
}

David J. Chato

Glenn Research Center, Cleveland, Ohio 


\section{NASA STI Program . . . in Profile}

Since its founding, NASA has been dedicated to the advancement of aeronautics and space science. The NASA Scientific and Technical Information (STI) program plays a key part in helping NASA maintain this important role.

The NASA STI Program operates under the auspices of the Agency Chief Information Officer. It collects, organizes, provides for archiving, and disseminates NASA's STI. The NASA STI program provides access to the NASA Aeronautics and Space Database and its public interface, the NASA Technical Reports Server, thus providing one of the largest collections of aeronautical and space science STI in the world. Results are published in both non-NASA channels and by NASA in the NASA STI Report Series, which includes the following report types:

- TECHNICAL PUBLICATION. Reports of completed research or a major significant phase of research that present the results of NASA programs and include extensive data or theoretical analysis. Includes compilations of significant scientific and technical data and information deemed to be of continuing reference value. NASA counterpart of peer-reviewed formal professional papers but has less stringent limitations on manuscript length and extent of graphic presentations.

- TECHNICAL MEMORANDUM. Scientific and technical findings that are preliminary or of specialized interest, e.g., quick release reports, working papers, and bibliographies that contain minimal annotation. Does not contain extensive analysis.

- CONTRACTOR REPORT. Scientific and technical findings by NASA-sponsored contractors and grantees.
- CONFERENCE PUBLICATION. Collected papers from scientific and technical conferences, symposia, seminars, or other meetings sponsored or cosponsored by NASA.

- SPECIAL PUBLICATION. Scientific, technical, or historical information from NASA programs, projects, and missions, often concerned with subjects having substantial public interest.

- TECHNICAL TRANSLATION. Englishlanguage translations of foreign scientific and technical material pertinent to NASA's mission.

Specialized services also include creating custom thesauri, building customized databases, organizing and publishing research results.

For more information about the NASA STI program, see the following:

- Access the NASA STI program home page at http://www.sti.nasa.gov

- E-mail your question via the Internet to help@sti.nasa.gov

- Fax your question to the NASA STI Help Desk at 301-621-0134

- Telephone the NASA STI Help Desk at 301-621-0390

- Write to:

NASA STI Help Desk

NASA Center for AeroSpace Information 7121 Standard Drive Hanover, MD 21076-1320 
NASA/TM-2006-214261

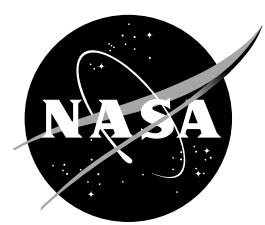

\section{The Role of Flight Experiments in the Development of Cryogenic Fluid Management Technologies}

David J. Chato

Glenn Research Center, Cleveland, Ohio

Prepared for the

21st Space Cryogenics Workshop

sponsored by the Cryogenic Society of America

Colorado Springs, Colorado, August 24-26, 2005

National Aeronautics and

Space Administration

Glenn Research Center

Cleveland, Ohio 44135 
Level of Review: This material has been technically reviewed by technical management.

Available from

NASA Center for Aerospace Information

7121 Standard Drive

Hanover, MD 21076-1320
National Technical Information Service 5285 Port Royal Road Springfield, VA 22161

Available electronically at http://gltrs.grc.nasa.gov 


\title{
The Role of Flight Experiments in the Development of Cryogenic Fluid Management Technologies
}

\author{
David J. Chato \\ National Aeronautics and Space Administration \\ Glenn Research Center \\ Cleveland, Ohio 44135
}

\begin{abstract}
This paper reviews the history of cryogenic fluid management technology development and infusion into both the Saturn and Centaur vehicles. Ground testing and analysis proved inadequate to demonstrate full scale performance. As a consequence flight demonstration with full scale vehicle was required by both the Saturn and Centaur programs to build confidence that problems were addressed. However; the flight vehicles were highly limited on flight instrumentation and the flight demonstration "locked-in" the design without challenging the function of design elements. Projects reviewed include: the Aerobee Sounding Rocket Cryogenic Fluid Management (CFM) tests which served as a valuable stepping stone to flight demonstration and built confidence in the ability to handle hydrogen in low gravity; the Saturn IVB Fluid Management Qualification flight test; the Atlas Centaur demonstration flights to develop two burn capability; and finally the Titan Centaur two post mission flight tests.
\end{abstract}

\section{Introduction}

This paper will review the history of technology development and infusion into both the Saturn and Centaur vehicles. It will examine what technologies were used, what technologies were abandoned, and what level of risk was assumed. At the beginning of the space age there were a number of unknowns in regards to handling cryogenic fluids in low gravity. Some of the main issues were propellant slosh, settling, and short-term storage/pressure control. Analytical modeling, drop tower experiments (ref. 1), and subscale experiments carried out on the Mercury missions (ref. 2) provided vital information but could not resolve answers with sufficient accuracy and comprehensiveness to ensure success with fullscale vehicles. As a consequence first sounding rocket tests, and then full scale flight development tests were undertaken. This paper will summarize the results of these tests, as well as the lessons learned from them. This will serve as a guide as we re-enter the low gravity world with new vehicles by reviewing the advantages and limitations of low gravity flight demonstrations.

\section{Aerobee Sounding Rocket Cryogenic Fluid Management (CFM) Tests}

\section{History}

In the early sixties, a series of sounding rocket tests were conducted to understand the behavior of liquid hydrogen in low gravity. The test equipment was capable of observing behavior in a 9 in. spherical tank partially filled with liquid hydrogen undergoing an acceleration $10^{-4}$ times smaller than normal gravitational acceleration for approximately $5 \mathrm{~min}$. Nine flights were conducted but the results of only seven have been published in the open literature (refs. 3 to 9). Flight test of a very similar 9 in. hydrogen tank was conducted in a secondary payload pod attached to an Atlas intercontinental ballistic missile which provided for $21 \mathrm{~min}$ of free fall (ref. 10). Unfortunately residual rotation of the pod produced an acceleration of only $10^{-3}$ times normal gravity. Aydelott conducted a ground test with a similar 9 in. spherical tank and used the results from all three tests to develop simple models of hydrogen tank pressure rise in low gravity (refs. 11 and 12). An illustration of the Dewar portion of the flight experiment is shown in figure 1. Experimental hardware and instrumentation are listed in table 1. 


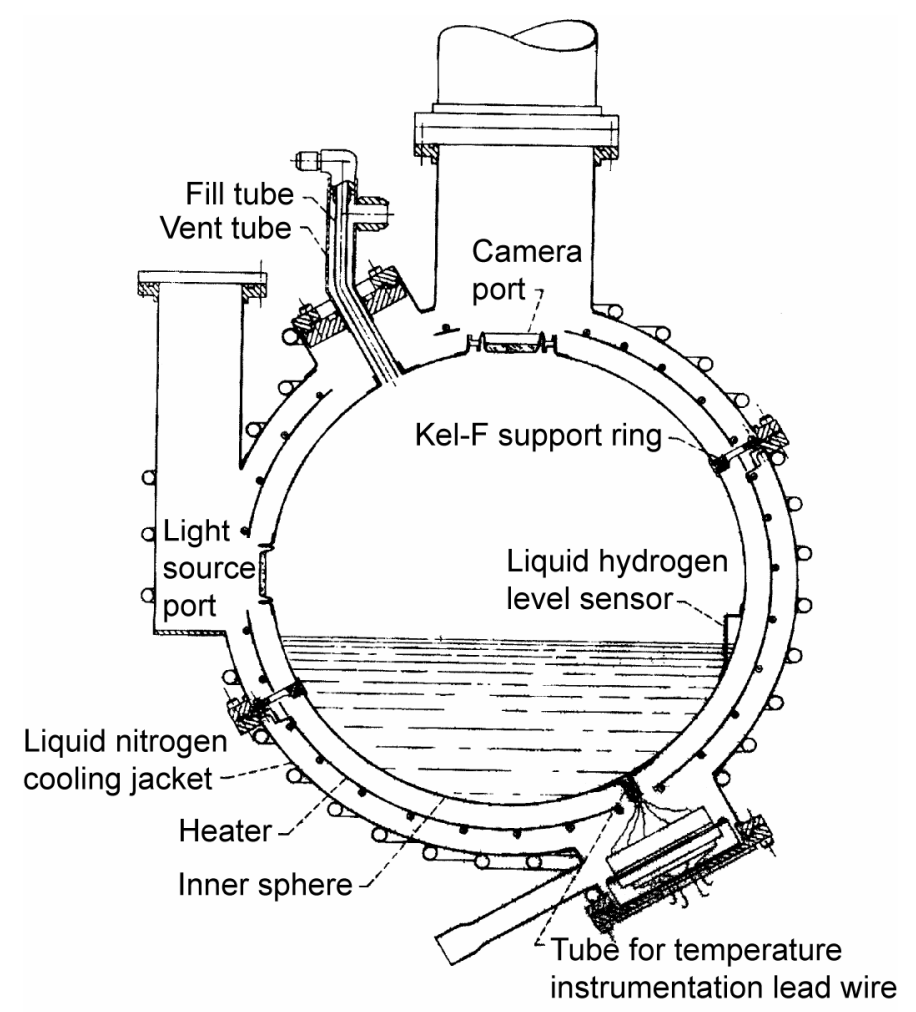

Figure 1.-Aerobee spherical tank assembly sketch.

TABLE 1.-EXPERIMENTAL APPARATUS

\begin{tabular}{|l|}
\hline \multicolumn{1}{|c|}{ Hardware } \\
\hline 9 in. diameter spherical tank \\
\hline $\begin{array}{l}10 \text { in. diameter shield with heater strips and liquid nitrogen cooling coils } \\
\text { (ground use only) }\end{array}$ \\
\hline 11 in. diameter vacuum jacket \\
\hline Ports for lights and camera \\
\hline Liquid hydrogen fill and drain lines \\
\hline De-spin table \\
\hline 18 wall mounted temperature transducers \\
\hline 1 g level sensor \\
\hline Camera \\
\hline 4 Accelerometers \\
\hline Pressure transducer \\
\hline
\end{tabular}

\section{Results}

Key parameters of the flight program are summarized in table 2. Important results included: the observation of nucleate boiling in hydrogen in low gravity, the observation of the collection of liquid hydrogen via a standpipe in low gravity, and the measurement of pressure rise in low gravity. Aydelott's comparison to ground testing indicated that neither ground nor flight pressure rise rates could be predicted by either a homogenous mixture model or a surface evaporation model. However, in this size of tank the actual pressure rise was bounded on the high end by the surface evaporation. He also found that ullage heating was an important factor in the pressure rise rate. 
TABLE 2.-KEY PARAMETERS OF AEROBEE FLIGHT PROGRAM

\begin{tabular}{|c|c|c|c|c|}
\hline Flight & $\begin{array}{l}\text { Fill } \\
(\%)\end{array}$ & $\begin{array}{c}\text { Heat flux } \\
\text { (btu/sq ft hr) }\end{array}$ & Film & Comments \\
\hline 1 & 22.5 & 270 & Film not recovered & Spinning at $2.5 \mathrm{cps}$ \\
\hline 2 & 32 & 132 & $\begin{array}{l}\text { Light Source dimmed by electrical } \\
\text { failure at } 120 \mathrm{sec} \text {. Light source } \\
\text { failed at } 194 \mathrm{sec} \text {. Surface motion } \\
\text { obscured by liquid over camera port }\end{array}$ & $\begin{array}{l}\text { Electrical problems with } \\
\text { electric spin table resulted in } \\
\text { tank spin-up from } 186 \text { to } \\
199 \mathrm{sec} \text { and } 212 \text { to } 326 \mathrm{sec}\end{array}$ \\
\hline 3 & 32 & 132 & $\begin{array}{l}\text { No Light Source Failure prior to low } \\
\text { gravity portion }\end{array}$ & $\begin{array}{l}\text { Contained unsuccessful } \\
\text { prototype zero gravity level } \\
\text { sensor }\end{array}$ \\
\hline 4 & 25.1 & 61.5 & Yes & Only $1 / 2$ of tank heated \\
\hline 6 & 20.6 & 267 & Yes & $\begin{array}{l}\text { Spinning at } 2.73 \mathrm{cps} \\
\text { contained standpipe for } \\
\text { liquid acquisition. Only } 1 / 2 \\
\text { of tank heated }\end{array}$ \\
\hline 7 & 36 & 23 & No Camera Port & $\begin{array}{l}\text { Liquid position determined } \\
\text { by four sets of internal } \\
\text { temperature rakes (four } \\
\text { sensors per rake) }\end{array}$ \\
\hline 9 & 78.3 & 145 & Yes & \\
\hline Atlas pod & 36 & 25 & No Camera Ports & $\begin{array}{l}\text { Liquid position determined } \\
\text { by four sets of internal } \\
\text { temperature rakes (four } \\
\text { sensors per rake) }\end{array}$ \\
\hline
\end{tabular}

\section{Lessons Learned}

Issues encountered included de-spin problems, lighting failures, liquid retention in liquid-vapor sensors, and loss of camera film. Although Aydelott found the surface evaporation as an upper bound for this size tank, subsequent flight test of full size tanks produced even higher pressure rise rates. Analysis of the full scale data linked the issue to the other finding of Aydelott that ullage heating controlled the pressure rise rate. Despite these difficulties, overall the projects served as a valuable stepping stone to flight demonstration and built confidence in the ability to handle hydrogen in low gravity. Using the camera and temperature sensors as the main instruments of observing low-g behavior will appear again in our discussion of subsequent experiments.

\section{Saturn IVB Fluid Management Qualification}

\section{Background}

The Apollo Lunar mission required the Saturn IVB stage to have a capability to coast in low earth orbit for up to $41 / 2 \mathrm{hr}$ then restart. To obtain this capability it was necessary to maintain liquid over the engine feedlines and cool the engine feedlines down prior to engine restart. A strategy was developed to maintain continuous liquid settling during the coast period. After engine cutoff, the propellants were settled by $5 \times 10^{-4} \mathrm{~g}$ thrust for $77 \mathrm{sec}$ (the pair of $311 \mathrm{~N}$ ullage rockets on Saturn were emulated by oxygen tank vent in the test flight.) After the initial transition to low gravity, the liquid position was maintained by continuous hydrogen venting producing $2 \times 10^{-5} \mathrm{~g}$. Due to the lack of understanding of the low gravity phenomena, a dedicated flight demonstration was conducted (refs. 13 to 17). The objectives of the flight demonstration were:

- Verify low gravity performance of S-IVB stage

- Obtain data on heat transfer and fluid behavior in reduced gravity 
Experimental apparatus are listed in table 3. Key instrumentation included a television camera. The TV signal was down linked to ground stations in Corpus Christi, Kennedy Space Center, Bermuda, and Carnarvon, Australia. The first three stations provided a band of 14 min of continuous coverage when the stage was above them, so most experiments were conducted during this portion of the orbit.

\begin{tabular}{|l|} 
TABLE 3.-SATURN EXPERIMENT APPARATUS \\
\begin{tabular}{|l|}
\hline \multicolumn{1}{|c|}{ Hardware } \\
\hline S-IVB stage launched on S-IB rocket. Off load of oxygen tank to provide \\
$2,2273 \mathrm{~kg}$ LOX and $8,636 \mathrm{~kg} \mathrm{LH}$ at orbit insertion \\
\hline \multicolumn{1}{|c|}{ Instrumentation } \\
\hline TV system \\
\hline 57 temperature sensors \\
\hline 9 pressure sensors \\
\hline 7 liquid-vapor sensors \\
\hline 5 accelerometers \\
\hline 3 calorimeters \\
\hline
\end{tabular}
\end{tabular}

\section{Results}

The mission known as AS-203 was launched July 5, 1966. It achieved all of its objectives. Table 4 shows the matrix of experiments conducted. Detailed findings follow.

\begin{tabular}{|l|l|}
\multicolumn{1}{|c|}{ TABLE 4.- } \\
\hline Orbit & \multicolumn{1}{c|}{ Experiment } \\
\hline First & Liquid dynamics part 1 \\
\hline & Engine chilldown hydrogen line chilldown 1 \\
\hline & Engine chilldown oxygen line chilldown \\
\hline Second & Liquid dynamics part 2 \\
\hline & Engine chilldown hydrogen line chilldown 1 \\
\hline Third and Fourth & Liquid motion after thrust termination \\
\hline & Rapid depressurization \\
\hline & Closed tank experiment \\
\hline
\end{tabular}

\section{Liquid Dynamics}

Two slosh waves were detected after the boost phase termination. The sources of the waves were attributed to:

- Amplification of boost phase slosh

- Possible surge from fuel suction duct

Both slosh waves were caught by the deflector. Both waves damped after $73 \mathrm{sec}$.

No disturbances were detected after switching to the hydrogen vent thrusters. The liquid surface began boiling at $166 \mathrm{sec}$ into the flight resulting in vapor fog. The hydrogen vent system provided adequate control of liquid position during the required coast period.

\section{Engine Chilldown}

First hydrogen line chilldown:

- Hydrogen line cooled by $290 \mathrm{sec}$ of recirculation with recirculation pump

- $20 \mathrm{sec}$ of prevalve with recirculation

- $10 \mathrm{sec}$ prevalve no recirculation

- $12.5 \mathrm{sec}$ of outflow 
The chilldown transients were less severe than ground testing. In flight chilldown was achieved prior to opening the prevalve even though the prevalve had been necessary in ground testing to chilldown the engine.

Oxygen line chilldown:

- $290 \mathrm{sec}$ recirculation cooling

- $12.2 \mathrm{sec}$ prevalve open with recirculation

- $51 \mathrm{sec}$ outflow

Oxygen line chilldown was achieved. However unstable recirculation flow occurred near the end of recirculation period due to the low oxygen level remaining in the tank. This was not considered a serious problem since it was know the oxygen level would be much higher in the actual mission flights.

Second hydrogen line chilldown:

- Timeline was the same as first but without outflow. Lack of subcooling in the hydrogen made the recirculation pump flow highly variable. Hardware temperatures were lower than expected throughout flight due engine retaining liquid in the low gravity environment.

\section{Liquid Motion After Settling Thrust Termination}

During free coast a drag deceleration of approximately $1.9 \times 10^{-6}$ (Bond number 7) caused liquid to reorient to the forward end. After 5 min the liquid was resettled via the oxygen vent thrusters, and the hydrogen vent thrusters restarted.

\section{Rapid Depressurization}

First Blow Down ( 3 min under $3.7 \times 10^{-4} \mathrm{~g}$ ) of the tank produced a fog, then large liquid blobs in the ullage, even though bulk fluid remained settled. Second and third blow-down ( $90 \mathrm{sec}$ each under $2 \times 10^{-5} \mathrm{~g}$ ) produced behavior similar to the first blow-down. Boiling of saturated bulk liquid caused only a $15.9 \mathrm{kPa}$ pressure drop in the third blow-down.

\section{Closed Tank Experiment}

The closed tank experiment was started with $7,273 \mathrm{~kg}$ of hydrogen at $85.5 \mathrm{kPa}$. It reached $260 \mathrm{kPa}$ in $5,360 \mathrm{sec}$ with an average rise rate of $117.2 \mathrm{kPa} / \mathrm{hr}$ (predicted was $22.1 \mathrm{kPa} / \mathrm{hr}$.) The rupture of the common bulkhead between the oxygen and hydrogen was believed to have exploded the tank at a delta $\mathrm{p}$ of $241 \mathrm{kPa}$ when the signals from stage were lost 22,680 sec after liftoff.

\section{Lessons Learned}

The Saturn IVB flight experiment was very successful in achieving the goals laid out for it, but several issues arise for future designers. Since the stage performed the nominal mission as expected, no changes to the design were required for the actual Apollo missions. Continuous settling via vent thrusters achieved both the objective of maintaining liquid positioning and tank pressure control at the cost of a considerable amount of lost hydrogen. However, the experiments at the end of the mission indicated that recovering liquid from a low gravity coast was relatively easy, so continuous settling was probably not required. The engine chilldown tests although effective, gave another indication of over-design. The engines cooled much faster than the estimates based on preflight ground testing predicted. The experiment did provide a good source of data for benchmarking both slosh and pressure control modeling efforts. 


\section{Flight Qualification of Centaur CFM}

\section{Background}

It was determined that the launch window for the Surveyor missions could be significantly enhanced by adding an orbital coast and an engine restart in low gravity. Based on the available information a test flight designated AC -4 was conducted. Two $8.90 \mathrm{~N}$ thrusters (producing a Bond number of 240 in the hydrogen tank) were added to the basic Centaur to provide settling thrust throughout coast. However, propellant disturbances at the main engine cut-off caused liquid entrainment in the vent. As a result the spacecraft tumbled out of control. To correct these difficulties a number of new systems were added to a second test flight designated as $\mathrm{AC}-818$. Table 5 details the $\mathrm{AC}-8$ hardware and instrumentation.

TABLE 5.-ATLAS-CENTAUR 8 EXPERIMENT CONCEPT
\begin{tabular}{|l|}
\hline \multicolumn{1}{|c|}{ Hardware } \\
\hline Centaur stage with equipment added to prevent boost phase surge including: \\
\hline Dissipater on volute bleed \\
\hline Recirculation line dissipater \\
\hline Pressurant gas diffuser \\
\hline Slosh baffle channel ring with 12 anti-swirl baffles \\
\hline Settling thrust increased to $444 \mathrm{~N}$ for 100 sec after main engine cutoff \\
\hline Settling thrust upped to $26.7 \mathrm{~N}$ for coast phase (Bond number 360) \\
\hline \\
\hline 32 custom liquid-vapor sensors \\
\hline 16 custom ullage temperature sensors \\
\hline 45 wall mounted temperature sensors \\
\hline Absolute pressure and vent gas temperature in each vent \\
\hline 5 calorimeters \\
\hline Two accelerometers \\
\hline 2 pressure transducers each tank \\
\hline
\end{tabular}

\section{Results}

AC-8 demonstrated successful propellant retention for the entire coast phase. At $917 \mathrm{sec}$ into the experiment irregularities in two of the four settling thrusters caused a backup pair of $222 \mathrm{~N}$ thrusters to fire. The $222 \mathrm{~N}$ thrusters then set up a slosh wave that persisted for four cycles $(532 \mathrm{sec})$ figure 2 shows the liquid position as measured by the internal level sensors during the first propellant slosh wave cycle. The AC-8 propellant sidewall heat flux was measured at rates from 18.9 to $31.5 \mathrm{~W} / \mathrm{m}^{2}$. Forward heat flux was measured from 69 to $136 \mathrm{~W} / \mathrm{m}^{2}$. Due to a failure unrelated to the CFM systems, successful engine restart was not achieved. Successful engine restart was demonstrated on the following test flight AC-9.

\section{Lessons Learned}

Subscale modeling and drop tower analyses suggested that a Bond number of 240 would be adequate to address the steady-state settling requirements. Unfortunately the deciding parameter turned out to be the slosh transient at the start of the low gravity coast. To provide a quick fix, all possible sources of the problem were addressed and then tested together. Unfortunately, a systematic investigation of each problem to determine the real culprits and the minimum requirements for correcting the problem were not undertaken. Due to the cost and complexity of flight testing, once $\mathrm{AC}-8$ proved that the problems were addressed no further investigation of the boost phase surge was conducted. 


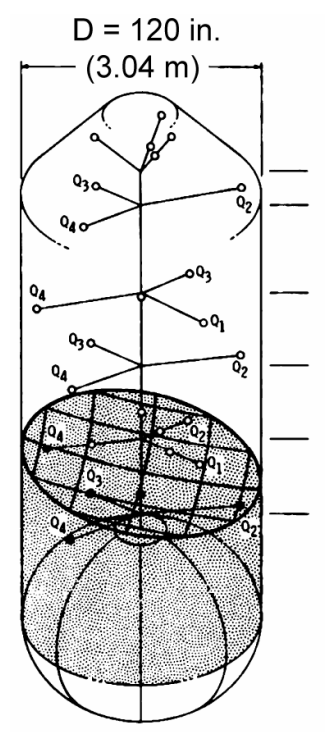

(a)

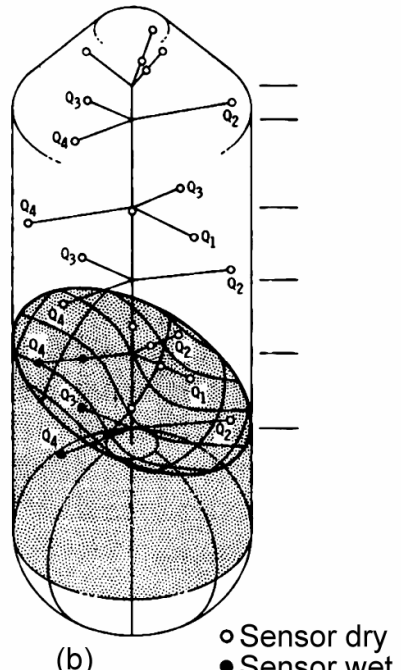

(b)

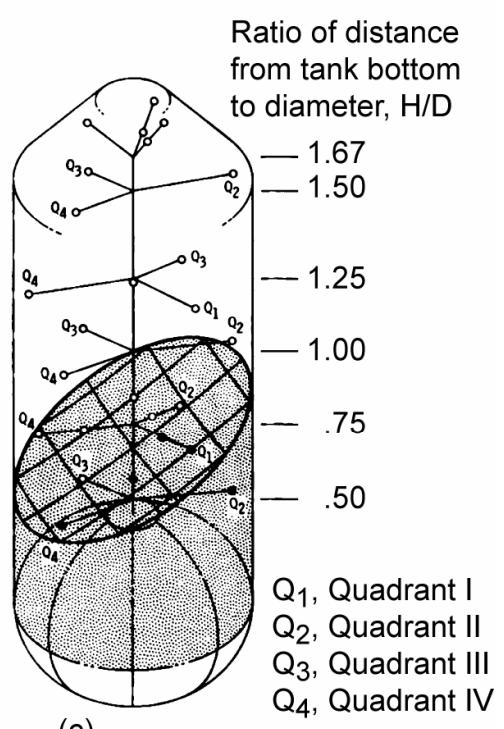

(c)

Figure 2.-Liquid position in AC-8 hydrogen tank during first slosh wave 919 to 1062 seconds after first main engine cut-off. (a) Time, $955 \mathrm{sec}$. (b) Time, $995 \mathrm{sec}$. (c) Time, $1060 \mathrm{sec}$.

\section{Titan Centaur CFM Flight Tests}

\section{Background}

Excess payload capacity made propellant available for extended mission testing of the Titan-Centaur upper stage. Two test flights were conducted TC-219 and TC-520-21. Propellants available were: 17 percent of the hydrogen for TC-2: 14.5 percent of the hydrogen and 12 percent of the oxygen for TC -5 . Table 6 shows the hardware and instrumentation for these test flights. Test planned for TC -2 and TC -5 are shown in table 7.

\section{TABLE 6.-TITAN-CENTAUR EXPERIMENT CONCEPT}

\begin{tabular}{|l|}
\hline \multicolumn{1}{|c|}{ Hardware } \\
\hline Modifications to Centaur upper stage for Titan Centaur \\
\hline Three Layer MLI sidewall insulation to reduce $\mathrm{LH}_{2}$ heating from 8,205 to $146 \mathrm{~W}$ \\
\hline Two 26.7 $\mathrm{N} \mathrm{H}_{2} \mathrm{O}_{2}$ thrusters for liquid collection after coast (Bond number 990) \\
\hline Vent control system \\
\hline Revised tank pressurization technique to reduce pressurant consumption \\
\hline \multicolumn{1}{|c|}{ Instrumentation } \\
\hline 12 liquid-vapor sensors in the hydrogen tank \\
\hline Pressure gauge \\
\hline Ullage temperature Sensors both $\mathrm{LH}_{2}$ and LOX tank \\
\hline
\end{tabular}


TABLE 7.-TITAN-CENTAUR PLANNED TESTS

\begin{tabular}{|l|l|}
\hline \multicolumn{1}{|c|}{ TC-2 } & \multicolumn{1}{c|}{ TC-5 } \\
\hline 1 hr zero-g coast & $5.25 \mathrm{hr}$ coast \\
\hline Settling maneuver & Settling maneuver \\
\hline Engine Restart & Engine restart \\
\hline 3 hr coast & 30 min coast \\
\hline Settling maneuver & Settling maneuver \\
\hline Engine restart & Engine restart \\
\hline & 20 min coast \\
\hline & Settling maneuver \\
\hline & Engine restart \\
\hline & 5 min settled coast \\
\hline & Engine start \\
\hline & 2 hr coast \\
\hline & Engine restart \\
\hline &
\end{tabular}

\section{Results}

TC-2 was launched on December 10th, 1974. Liquid position was quite different than the pretest prediction during the first coast, due to liquid retention in the crevice section of the hydrogen tank. Figure 3 shows the estimated liquid position based on level sensor readings and a mass balance. Settling thrust was high enough to cause a column of liquid to flow along the centerline as well as flow along the tank wall. The liquid collected in $40 \mathrm{sec}$ rather than the pretest prediction of 110 or the scheduled thruster firing of $300 \mathrm{sec}$. No venting was required. Engines were restarted successfully.

During the second coast, liquid position was very similar to that observed in the first coast. At $8560 \mathrm{sec}$ into the coast, settling thrusters were fired for $180 \mathrm{sec}$. Liquid again collected in about $40 \mathrm{sec}$. After settling, the tank was vented for $40 \mathrm{sec}$, during the vent the topmost liquid sensor rewet. The liquid distribution in the tank returned the previous position for a continued coast of $1590 \mathrm{sec}$. Then the settling thruster fired again collecting the liquid in $37 \mathrm{sec}$. Following the settling the main engines were successfully restarted.

TC-5 was launched on January 15, 1976. During the first coast, the liquid behavior was very similar to TC-2. Liquid was settled after $20 \mathrm{sec}$ of thruster firing and the engine was successfully restarted. After firing, the liquid returned to the previous liquid position. After the second coast, the liquid was settled by $20 \mathrm{sec}$ of thruster firing and engine successfully restarted again. After this engine firing, insufficient liquid was available to rewet the forward end. The liquid remained trapped in the hydrogen tank crevice for the remainder of the flight. All remaining engine starts were successful although the engine burn started after the short settled coast (fourth coast) showed significant cavitation in the oxygen boost pump. This was attributed to a start transient caused by not letting the boost pump spin down prior to engine start.

Overall, testing indicated it was perfectly feasible to allow the centaur to coast in micro gravity then use settling thrust to collect the liquid prior to restart. TC-2 conducted two additional engine firings with coast times as long as $3 \mathrm{hr}$ coast time. TC-5 demonstrated five additional engine firings with coasts as long as $5.25 \mathrm{hr}$. The TC-5 mission of $91 / 2 \mathrm{hr}$ is still the longest Centaur mission conducted.

\section{Lessons Learned}

The Titan Centaur CFM tests provided a wealth of information on the performance of propellants in low gravity and demonstrated long coast capabilities with fairly simple modifications. The "piggy backing" on operational missions made them reasonable cost but prevented them from carrying as extensive instrumentation as the previous Atlas test flights. Surprisingly although TC-2 and TC -5 indicated clearly the possibility of a three burn mission to geosynchronous orbit, this capability was not implemented until the Titan Centaur IV more than 20 yr later. 


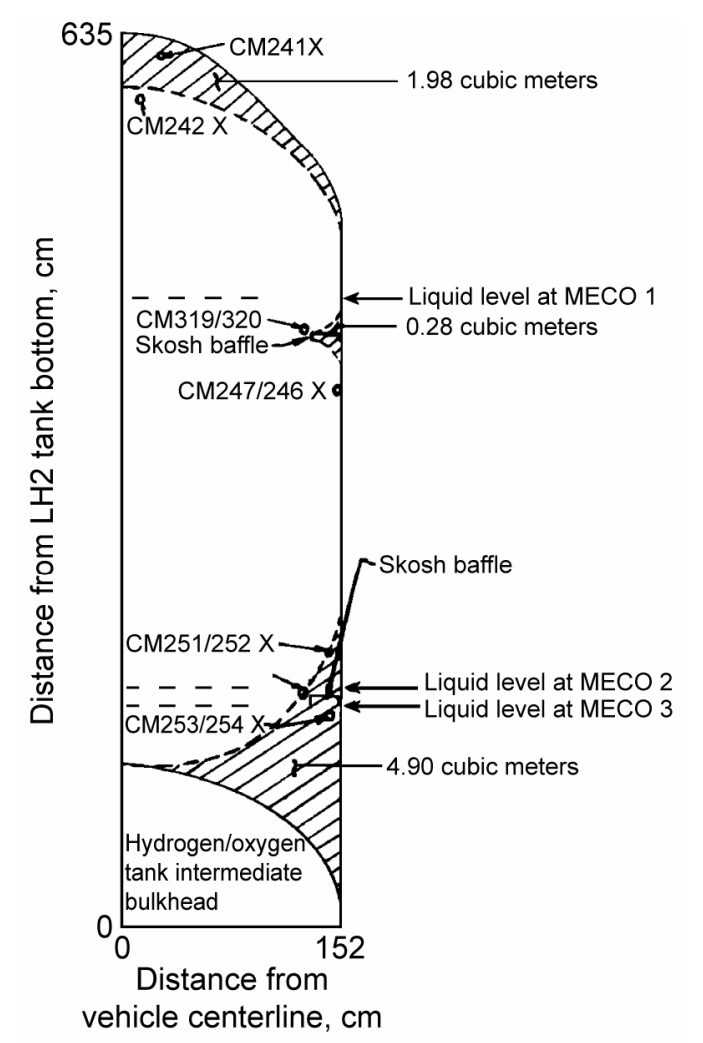

Figure 3.-Liquid hydrogen position during TC-2 first coast prior to propellant settling for vent.

\section{Summary}

Early sounding rocket tests with liquid hydrogen were able to build confidence in its storability and usability. Saturn was a point design, so technology for it was demonstrated on a single flight mission. Data from the demo flight provided a useful source of information for further research. Centaur has a long history of flight development and use. Demonstration flights to develop two burn capability were ongoing even as a single burn mission was being used to deliver Surveyor to the moon. Titan Centaur provided a vehicle for numerous development tests as well as two post mission flight tests. Data from these tests were gradually infused into the Centaur program including the peroxide elimination in the early 1980s, enhancements to the commercial Atlas, and finally implementation of a three burn capability on the Titan-Centaur IV (The three burn mission has long been a major goal of the centaur as it enables the entire LEO-GEO transfer to be performed by the Centaur stage alone.)

So far ground testing and analysis have proved inadequate to demonstrate low-gravity full scale performance in cryogenic upper stages. Sounding rocket testing provided a reasonable test bed for developing ideas and concepts with cryogenic fluids, but again could not be easily translated to full scale performance. As a consequence, flight demonstration with full scale vehicle was required by both the Saturn and Centaur programs to build confidence that problems were addressed and under control. However; the flight vehicles were highly limited on flight instrumentation and the flight demonstration "locked-in" the design without challenging the function of design elements. Direct video observation of liquid behavior proved possible on both the Aerobee and Saturn programs. Both Atlas-Centaur and TitanCentaur demonstrated that a few strategically placed level sensors were capable of providing a great deal of information on liquid motion in low gravity. Although advances in technology (for example computer modeling and miniature instrumentation) have advanced significantly from the era when these missions were launched, there still great deal to be learned from studying these missions. 


\section{References}

1. Otto, E.W. "Static and Dynamic Behavior of the Liquid-Vapor Interface During Weightlessness," Chemical Engineering Progress vol. 62 no. 611966.

2. Petrash, D.A., Nussle, R.C., and Otto E.W. "Effect of Acceleration Disturbances Encountered on the MA-7 Spacecraft on the Liquid-Vapor Interface in a Baffled Tank During Weightlessness." NASA TN D-1577, 1963.

3. R.H. Knoll, G.R. Smolak, and R.R. Nunamaker, "Weightless Experiments with Liquid Hydrogen in Aerobee Sounding Rockets; Uniform Radiant Heat Addition—Flight 1," NASA TM X-484, 1962.

4. J.G. McArdle, R.C. Dillon, and D.A. Altmos, "Weightless Experiments with Liquid Hydrogen in Aerobee Sounding Rockets; Uniform Radiant Heat Addition-Flight 2," NASA TM X-718, 1962.

5. R.R. Nunamaker, E.L. Corpas, and J.G. McArdle, "Weightless Experiments with Liquid Hydrogen in Aerobee Sounding Rockets; Uniform Radiant Heat Addition-Flight 3," NASA TM X-872, 1963.

6. J.D. Regetz Jr., M.J. Conroy, and R.G. Jackson, "Weightless Experiments with Liquid Hydrogen in Aerobee Sounding Rockets; Nonuniform Radiant Heat Addition-Flight 4," NASA TM X-873, 1964.

7. K.L. Abdalla, R.A. Flage, and R.G. Jackson, "Zero-gravity Performance of Ullage Control Surface with Liquid Hydrogen While Subject to Unsymmetrical Radiant Heating," NASA TM X-1001, 1964.

8. J.C. Aydelott, E.L. Corpas, and R.P. Gruber, "Comparison of Pressure Rise in a Hydrogen Dewar for Homogeneous, Normal-Gravity Quiescent, and Zero-Gravity Conditions—Flight 7,' NASA TM X1006, 1964.

9. J.C. Aydelott, E.L. Corpas, and R.P. Gruber, "Comparison of Pressure Rise in a Hydrogen Dewar for Homogeneous, Normal-Gravity Quiescent, and Zero-Gravity Conditions-Flight 9," NASA TM X$1052,1965$.

10. K.L. Abdalla, T.C. Frysinger, and C.R. Andracchio, "Pressure Rise Characteristics for a Liquid Hydrogen Dewar for Homogeneous, Normal-Gravity Quiescent, and Zero-Gravity Tests," NASA TM X-1134, 1965.

11. J.C. Aydelott, "Normal Gravity Self-Pressurization of 9-in. $(23 \mathrm{~cm})$ Diameter Spherical Liquid Hydrogen Tankage," NASA TN D-4171, 1967.

12. J.C. Aydelott, "Effect of Gravity on Self-Pressurization of Spherical Liquid-Hydrogen Tankage," NASA TN D-4286, 1967.

13. Anonymous, "Saturn IB Liquid Hydrogen Orbital Experiment Definition," NASA TM X-53158.

14. F.E. Swalley, G.K. Platt, and L.J. Hastings, "Saturn V Low Gravity Fluid Mechanics Problems and their Investigation by Full-Scale Orbital Experiment," In Fluid Mechanics and Heat Transfer Under Low Gravity, Lockheed June 1965.

15. F.E. Swalley, W.D. Ward, and L.E. Toole, "Low Gravity Fluid Behavior and Heat Transfer Results from the S-IVB-203 Flight," In "Proceedings of the Conference on Long-Term Cryo-Propellant Storage in Space," Marshall Space Flight Center, 1966.

16. H.J. Buchanan and F.M. Bugg "Orbital Investigation of Propellant Dynamics in a Large Rocket Booster," NASA TN D-3968, 1967.

17. Anonymous, "Evaluation of AS-203 Low Gravity Orbital Experiment," Chrysler Corporation, January 1967.

18. R.F. Lacovic, et al., "Management of Cryogenic Propellants in a Full-Scale Orbiting Space Vehicle," NASA TN D-4571, 1968.

19. R.F. Lacovic, "Centaur Zero Gravity Coast and Engine Restart Demonstration on the Titan/Centaur (TC-2) Extended Mission," NASA TM X-71821, 1975.

20. R.F. Lacovic, "Thermodynamic Data Report for the Titan/Centaur TC-5 Extended Mission.

21. R.F. Lacovic, "Propellant Management Report for the Titan/Centaur TC-5 Extended Mission," NASA TM X-73749, 1977. 


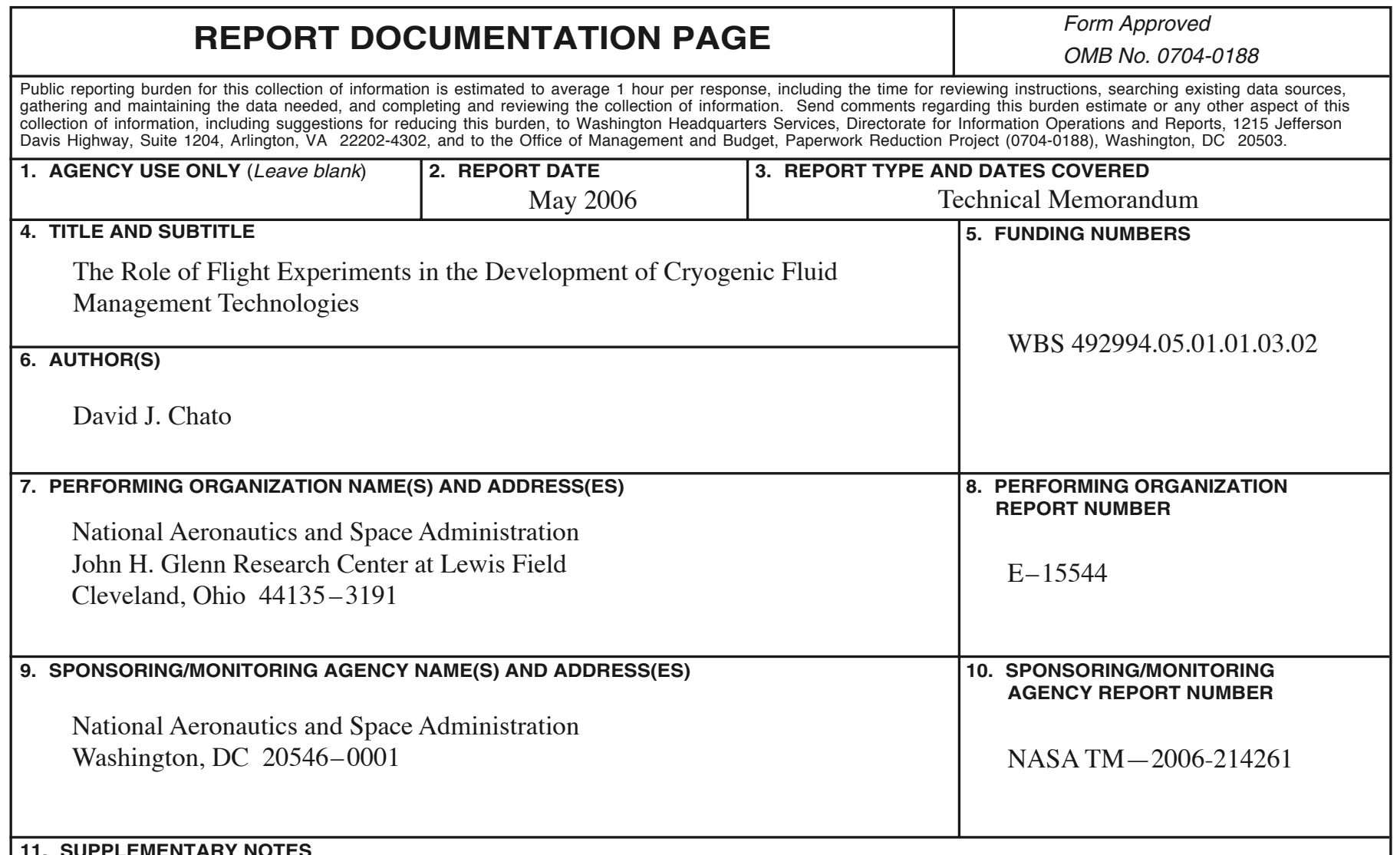

\section{SUPPLEMENTARY NOTES}

Prepared for the 21st Space Cryogenics Workshop sponsored by the Cryogenic Society of America, Colorado Springs, Colorado, August 24-26, 2005. Responsible person, David J. Chato, organization RTP, 216-433-7488.

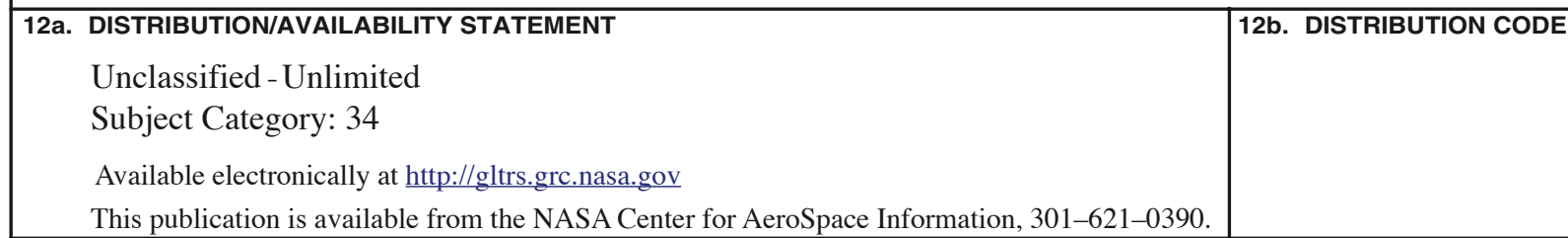

\section{ABSTRACT (Maximum 200 words)}

This paper reviews the history of cryogenic fluid management technology development and infusion into both the Saturn and Centaur vehicles. Ground testing and analysis proved inadequate to demonstrate full scale performance. As a consequence flight demonstration with a full scale vehicle was required by both the Saturn and Centaur programs to build confidence that problems were addressed. However; the flight vehicles were highly limited on flight instrumentation and the flight demonstration "locked-in" the design without challenging the function of design elements. Projects reviewed include: the Aerobee Sounding Rocket Cryogenic Fluid Management (CFM) tests which served as a valuable stepping stone to flight demonstration and built confidence in the ability to handle hydrogen in low gravity; the Saturn IVB Fluid Management Qualification flight test; the Atlas Centaur demonstration flights to develop two burn capability; and finally the Titan Centaur two post mission flight tests.

\begin{tabular}{|c|c|c|}
\hline \multicolumn{3}{|c|}{$\begin{array}{l}\text { 14. SUBJECT TERMS } \\
\text { Cryogenics; Launch vehicles; Flight deve }\end{array}$} \\
\hline $\begin{array}{l}\text { 17. SECURITY CLASSIFICATION } \\
\text { OF REPORT } \\
\text { Unclassified }\end{array}$ & $\begin{array}{l}\text { 18. SECURITY CLASSIFICATION } \\
\text { OF THIS PAGE } \\
\text { Unclassified }\end{array}$ & $\begin{array}{l}\text { 19. SECURITY CLASSIFICATION } \\
\text { OF ABSTRACT } \\
\text { Unclassified }\end{array}$ \\
\hline
\end{tabular}



